\title{
El espacio en los estudios sociales de la religión: perspectivas, objetos y problemas emergentes en las agendas de investigación latinoamericanas
}

\author{
O espaço nos estudos sociais da religião: \\ perspectivas, objetos e problemas emergentes \\ nas agendas de pesquisa latino americanas
}

María Eugenia Funes*

\begin{abstract}
Resumen: Este artículo tiene como propósito analizar las formas en que los estudios sociales de la religión en América Latina han abordado la relación entre religión y espacio. Se propondrá que el espacio ha sido una de las dimensiones emergentes en las agendas de investigación de la sociología y la antropología de la religión durante las últimas décadas y que estas investigaciones pueden distinguirse en tres tipos. En primer lugar, aquellas que estudian la distribución de las prácticas y símbolos religiosos en el espacio público serán descriptas en el primer apartado. En el segundo, se presentarán investigaciones que analizan el papel de la religión en relación con procesos de transformación territorial más amplios desde una mirada diacrónica. Por último, se identificarán trabajos que consideran al espacio y a la religión como dimensiones mutuamente influyentes que, a su vez, impactan en la construcción de identidades en las sociedades contemporáneas. Nos proponemos ofrecer una lectura sistematizada acerca de la multiplicidad de aristas en las que la dimensión espacial se vuelve relevante para la comprensión de la vida religiosa.
\end{abstract}

Palabras clave: Religión. Espacio. América Latina.

Resumo: O objetivo deste artigo é analisar as maneiras pelas quais os Estudos Sociais da Religião na América Latina abordaram a relação entre religiáo e espaço. Será proposto que o espaço tem sido uma das dimensóes emergentes nas agendas de pesquisa da Sociologia e Antropologia da Religião durante as últimas décadas. Dessa forma, essas investigaçóes podem ser distinguidas em três tipos. Em primeiro lugar, serão descritos na primeira seção aqueles que estudam a distribuição de práticas e símbolos religiosos no espaço público. Entáo, na segunda, serão apresentadas investigações que analisam o papel da religião em relação a processos mais amplos de transformação territorial a partir de uma perspectiva diacrônica. Por fim, serão identificados trabalhos que considerem ao espaço e à religiâo como dimensões mutuamente influentes que têm efeitos sobre a construção de identidades nas sociedades contemporânea. Propomos oferecer uma leitura sistematizada sobre a multiplicidade de arestas nas quais a dimensão espacial torna-se relevante para a compreensão da vida religiosa.

Palavras-chave: Espaço. Religiáo. América Latina.

Doutora.em Ciencias Sociales (UBA) e Sociology (EHESS). Professora de Sociología de la Religión y Aantropología na USAL (Argentina). Orcid: 0000-0002-2980-6396 - Contato: marufunes28@gmail.com. 


\section{Introducción}

A pesar de su presencia en estudios sociales clásicos ${ }^{1}$ (Halbwachs, 2015), la pregunta por el espacio como una dimensión significativa del fenómeno religioso no ha vuelto a emerger en las agendas de investigación latinoamericanas hasta sólo algunas décadas atrás. Durante los últimos quince años el problema de la relación entre la vida religiosa y la configuración del espacio ha recibido la atención de numerosos investigadores e investigadoras de la región. Esta atención sobre el espacio coincide con la emergencia de prácticas religiosas caracterizadas por la semantización del espacio a través del movimiento de los creyentes en las agendas de investigación latinoamericanas, como las misiones (Ceriani Cernadas \& Lavazza, 2013, Seiguer, 2015, Flores 2018), las peregrinaciones (Steil y Tognol, 2016; Flores, 2017) y la construcción de santuarios (Ameigeiras, 2008).

Este artículo tiene como propósito presentar y revisar algunas de las investigaciones recientes que han abordado el vínculo entre religión y espacio en América Latina. Como se podrá observar a continuación, la pregunta por este vínculo tiene múltiples respuestas y ha dado lugar a la atención sobre numerosos objetos, procesos, grupos y abordajes diversos. Es por ello que presentaré tres conjuntos de investigaciones que comparten hipótesis y objetos de estudio similares².

El artículo se organizará, entonces, en tres apartados en los que se describirán tres formas diferentes en que investigadores e investigadoras latinoamericanas han abordado la relación entre las configuraciones del espacio y la vida religiosa ${ }^{3}$. En primer lugar, se hará referencia a un conjunto de trabajos que se proponen identificar las marcas que las prácticas y objetos religiosos depositan en el espacio. Estas investigaciones buscan, en general, describir la territorialización del pluralismo religioso en ámbitos urbanos de diferentes densidades. Esta atención sobre la expresión religiosa de la diversidad religiosa en las ciudades latinoamericanas permite, asimismo, mostrar los diferentes regímenes de visibilidad de los que gozan diferentes prácticas y grupos religiosos.

Un segundo conjunto de investigaciones se integra alrededor de las transformaciones que atraviesan la vida religiosa y la configuración del espacio en diferentes momentos

1 Maurice Halbwachs puede comprenderse como el primer sociólogo que aportó a la reflexión sobre la dimensión espacial de la vida religiosa en sus estudios sobre las morfologías religiosas y los procesos de sacralización de lugares desarrollados en movimientos de peregrinación. Para más información ver Halbwachs (2015).

2 La reciente atención sobre las relaciones entre espacio y religión por parte de las agendas de investigación lejos está de constituir un fenómeno exclusivamente latinoamericano. Las agendas de las academias de diferentes partes del mundo presentan también amplios e interesantes enfoques para pensar esta relación en otros contextos y en relación con sus particulares. Así, Hérvieu Léger (2002) ha construido una tipología de formas de espacialización de las instituciones religiosas, Becci, Burchardt y Giorda (2017) construyeron recientemente una tipología de estrategias espaciales de los grupos religiosos a partir del análisis de la presencia de diferentes prácticas y marcas religiosas ciudades alemanas e italianas, y Fer (2007) estudió las representaciones de la ciudad y los usos de las calles por parte de los evangélicos en la Polinesia francesa. Por otra parte, en los últimos ańos se han publicado varias compilaciones que presentan puntos de vista diversos construidos a partir de investigaciones en diferentes partes del globo. Ver, por ejemplo, Becci, Burchardt y Casanova (2013) y Garbin y Strhan (2017).

3 La selección de investigaciones aquí presentadas lejos está de ser exhaustiva. Los capítulos y artículos mencionados fueron seleccionados a los fines de ilustrar la diversidad de objetos y fenómenos que la atención sobre el espacio ha abierto para los estudios sociales de la religión en algunos países de América Latina. Asimismo, los elementos señalados de cada una de las investigaciones mencionadas constituyen sólo una parte de trabajos complejos y sistemáticos que son aquí sintetizados a los fines de construir nuestra tipología. 
históricos. Estas investigaciones están atravesadas entonces por la pregunta acerca del carácter diacrónico de ambas dimensiones y sus relaciones. Aquí se reúnen, también, investigaciones con referentes empíricos diversos: las formas en que los edificios religiosos son comprendidos por diferentes grupos sociales en contextos de transformación urbana, y el papel de las prácticas religiosas en procesos de diferenciación y segregación de determinados colectivos sociales. Asimismo, incluiremos dentro de este conjunto propuestas analíticas de gran alcance acerca de las transformaciones en la forma en que los grupos religiosos y el Estado han competido por la definición del territorio y de las subjetividades que lo habitan.

Finalmente, en el tercer apartado haremos referencia a investigaciones que comprenden a la religiosidad y al espacio como dimensiones mutuamente influyentes. Estas investigaciones se focalizan en la influencia de ambas dimensiones sobre los procesos de construcción de identidades colectivas y de modos de vida alrededor de un espacio particular. Al abordar escalas espaciales significativas para la vida cotidiana de los actores sociales, los y las autoras de este último grupo aportan a la comprensión de los roles que la religión juega en procesos sociales complejos como las migraciones transnacionales, la estratificación social y la conformación de redes de sociabilidad en las grandes urbes.

\section{La territorialización de las prácticas religiosas}

El primer eje alrededor del cual se ordenan las investigaciones que problematizan la relación entre religión y espacio está dado por la identificación de las marcas que instituciones y prácticas religiosas depositan en el espacio. Como se observará a continuación, estos trabajos se focalizan en dos tipos de objetos de estudio. Por un lado, varios se proponen identificar y describir la distribución de los símbolos religiosos en las ciudades latinoamericanas a través del análisis de su presencia en objetos "fijos", como publicidades, arte callejero, carteles, casas, mercados, edificios y grandes monumentos religiosos en plazas y vías de comunicación. Otros, en cambio, abordan las marcas que fenómenos religiosos "móviles" - como el turismo, las peregrinaciones, las misiones, los festivales y las predicaciones religiosas - depositan en el espacio. Muchas de estas investigaciones reflexionan sobre la configuración de la laicidad y la secularización en América Latina a partir de la presencia de marcas religiosas en diferentes espacios públicos de América Latina, y aportan al debate sobre los modos de regulación de las minorías religiosas en la región.

En la Argentina, esta primera perspectiva ha sido desarrollada por varios investigadores e investigadoras que se orientaron al estudio de los "modos de inscripción territorial" (Miguel, 2014: 196) de la religión en las ciudades. En primer lugar, las investigaciones reunidas en el "Atlas de las creencias religiosas en la Argentina" buscaron identificar las marcas que las identidades y prácticas religiosas depositan en el territorio de ese país (Giménez Béliveau \& Martínez, 2013). Para ello, se focalizaron en el estudio de los símbolos y rituales religiosos en el espacio público como vehículos para la comprensión de la forma en que lo religioso se proyecta en el espacio y la forma en que los creyentes hacen uso del espacio. Centrándose en el aspecto material de lo religioso, describieron 


\section{María Eugenia Funes}

la presencia de ermitas, carteles, santuarios, graffitis y calcos tanto en plazas y espacios comerciales como en áreas residenciales de diferentes ciudades del país. La comparación entre distintas ciudades del país llevó a estos autores a señalar diferencias en cuanto a los sectores de la ciudad en los que se localizan las marcas religiosas de diferentes denominaciones. Así, muestran que las zonas céntricas se diferencian de las residenciales en cuanto a la visibilidad de la diversidad religiosa local: mientras que los centros son los lugares donde se observa una mayor diversidad de marcas de numerosos grupos religiosos, los símbolos que se observan en los ámbitos residenciales se reducen a los católicos, presentes en las fachadas de las viviendas, y a los evangélicos localizados en las puertas de los templos. Al mismo tiempo, mientras que las instituciones católicas tienen una importante presencia en los centros históricos, los templos evangélicos se extienden en los barrios residenciales (Martinez, Miguel y Remedi, 2013; Blazsek et al., 2013).

Por otra parte, señalan que si bien la ciudad de Buenos Aires presenta la mayor diversidad religiosa en términos cuantitativos, no todas las denominaciones religiosas gozan de los mismos regímenes de visibilidad. Así, la mayor cantidad de marcas religiosas en los espacios públicos de la ciudad corresponden al catolicismo y a la espiritualidad Nueva Era, mientras que los símbolos de otras prácticas, como las de las religiones afrodescendientes, permanecen ocultos (Frigerio, 2002; Carballo, 2008; Algranti, Calcagno, Giménez Béliveau \& Rubio, 2013). Este tipo de análisis permite reconstruir, a través de la descripción de la distribución de las marcas religiosas en la ciudad los diferentes regímenes de visibilidad de los que gozan grupos religiosos hegemónicos y minoritarios en el espacio público (Frigerio, 2002; Miguel, 2014).

Otras investigaciones se aproximaron a la relación entre espacio y religión a través del estudio de la distribución de las mercancías religiosas en la ciudad. Este es el caso de Bahamondes (2016) quien recientemente llamó la atención sobre la concentración y la diversidad de la oferta de mercancías religiosas y espirituales a partir del estudio del casco histórico de la ciudad de Santiago de Chile. Esta parte de la ciudad se consolidó como una referencia para los creyentes que utilizan esa parte de la ciudad para obtener los objetos necesarios para desarrollar rituales por su propia cuenta. Al igual que en el caso de la ciudad de Buenos Aires, este autor identifica en la ciudad de Chile un aumento de la visibilidad de las prácticas Nueva Era, especialmente aquellas que se basan en cosmologías orientales. Este trabajo incorpora al arco de las prácticas religiosas a las prácticas de adivinación, desarrolladas en espacios públicos y zonas comerciales de la ciudad en tiendas que son montadas diariamente. Asimismo, analiza las políticas de ordenamiento urbano que regulan los lugares de la ciudad y los momentos del día y de la semana en que pueden llevarse adelante determinadas prácticas religiosas. Esta investigación muestra, entonces, otra de las formas en que la espacialidad de la vida religiosa en una ciudad expresa los modos s de regulación de su diversidad religiosa. En este caso, a través de las regulaciones estatales de planeamiento urbano que establecen zonas habilitadas y vedadas para el desarrollo de diferentes prácticas religiosas.

Por su parte, Giumbelli (2014) analizó las controversias que la presencia pública de símbolos religiosos en distintas ciudades e instituciones brasileras genera en diferentes colectivos. El autor se concentra en los debates que se suscitaron alrededor de la construcción del monumento al Cristo Redentor en la ciudad de Río de Janeiro en 
la década de 1920; la presencia de crucifijos y espacios destinados a la práctica religiosa en recintos estatales, hospitales, aeropuertos, universidades, centros comerciales, y los medios masivos de comunicación. Este tipo de abordaje, focalizado en las controversias formadas alrededor de la presencia de símbolos religiosos en el espacio público tiene, para este antropólogo, la virtud de incorporar al análisis de la vida religiosa las transformaciones del campo religioso y las diferentes posiciones que se movilizan frente a la diversificación y la descatolización de la sociedad brasilera a lo largo del siglo XX. El foco en la presencia de símbolos religiosos en el espacio público puede ser una vía para comprender la configuración y las modalidades que asume la laicidad en diferentes países. Desde una perspectiva latouriana, Giumbelli (2014) propone, entonces, que los símbolos religiosos y las controversias que se forman en torno a su presencia en el espacio público forman parte de los procesos históricos de definición de lo religioso y de su relación con otras esferas de la realidad social.

Muchas de las investigaciones aquí mencionadas distinguen las marcas "fijas" que la vida religiosa deposita en la ciudad, de aquellas depositadas por fenómenos "móviles". Varios estudios recientes se orientan al estudio de las inscripciones que los actores que protagonizan fenómenos religiosos caracterizados por la movilidad - como el turismo, las peregrinaciones, las misiones, los festivales y las predicaciones religiosas- depositan en el espacio. En la Argentina, Flores (2012) estudió el caso de la ciudad de Luján, donde todos los ańos converge la mayor cantidad de peregrinos y turistas religiosos del país. A partir de la perspectiva de la geografía cultural, definió a esta ciudad como una "hierópolis", es decir, un sitio de peregrinación que se diferencia de otros sitios históricos por el dominio de lo espiritual sobre otros aspectos de la vida social, la división de la experiencia temporal en torno al eje sagrado-profano, la llegada de peregrinos desde distancias lejanas, la presencia de itinerarios definidos y organizados en torno a un centro sagrado (en este caso la Basílica de Luján) y la posesión de una relevancia política local. $\mathrm{Al}$ igual que en los estudios mencionados anteriormente, su investigación involucra la identificación de una serie de "geosímbolos" que contribuyen con la construcción de esta ciudad como un "lugar religioso". Este caso también muestra la manera en que el Estado, a través de políticas públicas de desarrollo urbano y de fomento del turismo religioso, habilita y promueve determinadas prácticas religiosas mientras oculta otras. Estos procesos contribuyen con la delimitación y diferenciación entre prácticas religiosas y espirituales hegemónicas y subalternas, aspecto de la diversificación del campo religioso que presenta, entonces, una expresión espacial.

Tanto las marcas "fijas" como las "móviles" forman parte de la tipología de formas de territorialización religiosa propuesta por Suárez (2017) a partir del estudio de la "geografía" de la práctica religiosa en una colonia popular de la ciudad de México. Estos tipos ideales permiten abordan la relación entre espacio y religión a partir de la distinción de las zonas de la ciudad donde se desarrollan las prácticas religiosas, el tipo de edificaciones donde se estas se llevan adelante, su convivencia con otros usos del espacio público y doméstico, y la influencia de la religión en el uso del tiempo. Este autor enumera cinco formas de territorialización. En primer lugar, el anclaje oficial católico que se expresa en la presencia de templos y capillas ubicados en el centro de la ciudad. En segundo lugar, el anclaje de los templos protestantes y pentecostales caracterizado 
por el uso de espacios preexistentes, como salones de fiesta, domicilios y comercios, y la presencia de sus predicadores en distintos lugares de la ciudad y momentos de la semana. En tercer lugar, este autor distingue las expresiones de la religiosidad popular, compuestas de marchas fijas como nichos, ermitas y cruces dispersas por diferentes ámbitos públicos y privados de la ciudad. En cuarto lugar, se identifican las imágenes peregrinas que transitan por los barrios que pueden tener o no relación con las autoridades religiosas locales. Estas resignifican y sacralizan los espacios cotidianos, y reorganizan su temporalidad. Por último, la religión se territorializa en espacios íntimos a través de altares e imágenes presentes en los espacios domésticos.

Este primer conjunto de investigaciones se concentran, entonces, en el análisis de las marcas que distintas prácticas religiosas depositan en el espacio público. Su foco está puesto, en general, en la materialidad de la vida religiosa, compuesta por los símbolos en carteles, publicidades, arte callejero, mercancías, monumentos y edificaciones. Asimismo, problematizan la influencia de la religión en los usos del espacio urbano y muestran que la distribución y la (in)visibilidad de la vida religiosa en el espacio es, en parte, una expresión de los modos de regulación de lo religioso por el Estado y la sociedad civil.

\section{La vida religiosa y las transformaciones urbanas: miradas diacrónicas}

Si la categoría que atraviesa las investigaciones anteriores es la de espacio público, las investigaciones reunidas en este apartado están atravesadas por las categorías de ciudad, metrópolis y territorio. Éstas comparten una mirada diacrónica, lograda a través de la construcción de periodizaciones por medio de las cuales se compara la presencia y el impacto de lo religioso en el espacio en distintos contextos históricos y en relación con procesos urbanos más amplios. Al igual que en el apartado anterior, las investigaciones que describiremos a continuación dan cuenta las relaciones de poder que la espacialización de la vida religiosa expresa al mostrar los diferentes regímenes de subjetivación y de visibilidad que presentan los grupos religiosos, y al analizar el papel que juegan las prácticas religiosas en los procesos de segregación espacial en distintos contextos históricos. Estos estudios se apoyan en referentes empíricos diversos: las formas en que la religión ha influido sobre la vida cotidiana, la gestión del tiempo y la construcción identitaria en diferentes contextos históricos, las formas en que edificios y lugares de práctica religiosa son interpretados por proyectos de modernización urbana, la distribución de los grupos religiosos en la ciudad en relación con sus diferentes niveles de legitimidad social, las prácticas religiosas móviles desarrolladas por poblaciones subalternizadas.

Giumbelli, Haberle y Kerber $(2015)^{4}$ desarrollaron una perspectiva diacrónica al llamar la atención sobre la multiplicidad de formas en que la relación entre los edificios

4 Este fenómeno ha sido definido como un proceso de constitución de ciudades "post seculares" caracterizadas por una pluralidad de símbolos religiosa en el espacio público (Beaumont y Baker, 2011). Esta nueva configuración de las ciudades reemplaza, de acuerdo con estos autores, a las ciudades seculares desarrolladas a lo largo del siglo XX y caracterizadas por una retirada de la vida religiosa del ámbito urbano. 
religiosos y la transformación urbana es interpretada por diferentes colectivos en distintos contextos históricos. A partir del estudio de tres casos situados en la ciudad de Porto Alegre, estos autores estudiaron la manera en que distintos proyectos de modernización urbana interpretan el pasado, la relación entre la localización de los edificios religiosos y otras configuraciones sociales, y la forma en que comunidades, redes y agentes religiosas se posicionan frente a los proyectos de modernización urbana. Este análisis les permitió mostrar que el pasado, la tradición, la destrucción y la restauración son movilizados de diferentes maneras por arquitectos, intelectuales, líderes y creyentes religiosos, frente proyectos concretos de renovación urbana, dando lugar a "sobreposiciones de registros de reconocimiento patrimonial" (Giumbelli, Haberle y Kerber, 2015: 110). En primer lugar, abordaron los debates alrededor de los intentos de demolición de la Iglesia católica Nuestra Seńora de Rosario, ubicada en el centro de la ciudad. Frente a la amenaza de demolición como parte de un modelo de renovación urbana que buscaba eliminar "lo viejo" para dar lugar a estéticas, construcciones y organizaciones espaciales novedosas, emergieron discursos que defendían su cuidado y restauración en tanto parte del patrimonio arquitectónico de la ciudad y en tanto lugar de culto. El segundo de los casos estudiados, una iglesia evangélica construida en 1930 que intentó ser demolida para la apertura de avenidas en la década de 1990, permite a estos autores mostrar la movilización de argumentos que atribuían al edificio una relación con la identidad de la comunidad luterana y, por lo tanto, con la diversidad cultural de la ciudad. Finalmente, el análisis de los usos de los adeptos a las religiones de matriz afro y la renovación del Mercado Público Municipal expresan un proceso en el que el uso religioso por parte de una minoría segregada es interpretado como parte del patrimonio inmaterial de la ciudad. A través de este caso, los autores mostraron los efectos que las obras de restauración y modernización tuvieron en la visibilización de la tradición afrorreligiosa en la ciudad. A diferencia de los casos anteriores, aquí la modernización urbana estimuló la elaboración y sistematización de una tradición religiosa y dio visibilidad y reconocimiento a una religiosidad periférica. Así, estos autores señalaron la forma en que diferentes colectivos interpretan la presencia de distintos lugares de culto como parte de una ciudad en permanente crecimiento y transformación.

Por su parte, la mirada diacrónica de la espacialización de la religión ha permitido en algunos casos identificar relaciones de identidad y de mutuo refuerzo entre los procesos de segregación espacial y la distribución de las prácticas religiosas. Este es el caso de las investigaciones históricas desarrolladas por Nicoletti y Barelli (2014) y Núnéz y Barelli (2013) a partir del caso de las devociones marianas de distintos colectivos de inmigrantes en la ciudad patagónica de San Carlos de Bariloche. Nicoletti y Barelli (2014) proponen que las prácticas religiosas devocionales construyen territorios sagrados y contribuyen con los procesos de apropiación del territorio por parte de quienes se instalan en la ciudad. Asimismo, estas investigaciones exploraron la manera en que el traslado de las devociones marianas desde los lugares de origen hacia los lugares de destino, se constituyen como estrategias de visibilización en un contexto de marcada fragmentación socio-espacial en el que no solo las clases sociales sino también los migrantes provenientes de diferentes países limítrofes ocupan espacios materiales y simbólicos diferentes en el imaginario y la traza urbana de la ciudad (Núñez y Barelli, 2013). 
Así, el análisis de la distribución de las prácticas religiosas en el espacio permite a estos autores mostrar la forma en que éstas expresan y refuerzan las fronteras identitarias que se construyen entre distintos sectores de la población en diferentes contextos históricos.

Asimismo, el desarrollo de perspectivas diacrónicas acerca de las relaciones entre espacio y religión ha dado lugar a grandes caracterizaciones acerca de las diferentes formas que ella asume a lo largo del tiempo. Passos y Guerriero (2004) estudiaron la relación entre religión y espacio en el centro de San Pablo como parte de procesos más amplios de modernización y metropolización. Esta metrópoli, caracterizada en la actualidad por una pluralidad de templos, estilos y funciones religiosas, se formó sobre los restos de una pequeña ciudad colonial. Estos autores propusieron, entonces, que la modernidad implicó un cambio radical en la relación entre espacio y religión. Mientras que, durante la época colonial prevalecía el modelo de la "localidad", en el que la religión estructuraba el uso del tiempo, la vida cotidiana y las prácticas rituales de las comunidades con las que compartía el espacio, en la actualidad los espacios religiosos son uno entre otros elementos de un área metropolitana secularizada, desacralizada, y marcada por la influencia de la industria inmobiliaria. En este contexto, las grandes iglesias católicas de la época colonial, presentes en el centro de la ciudad, son definidas como espacios "sagrados envejecidos" que continúan recibiendo, al mismo tiempo, a un público católico y a grupos religiosos (esotéricos, afrobrasileros y evangélicos). Así, para estos autores, en la actualidad las metrópolis están configuradas por una pluralidad de sentidos y la religión se desarrolla por fuera de territorios definidos.

Por su parte Segato $(2007,2008)$ ha propuesto que en la actualidad asistimos a un proceso de transformación de las relaciones entre religiones y territorio que se inscribe en un proceso mayor de pérdida de la centralidad de los Estados Nacionales en la definición de los procesos de subjetivación en sus territorios. Desde una perspectiva foucaultiana, Segato sostuvo que el territorio presenta una relación dialéctica con la construcción de identidades. De acuerdo con su perspectiva, asistimos a la constitución de un nuevo orden territorial en el que los dispositivos pastorales de gobierno de la población -propios de la modernidad y caracterizados por el control de la definición de las identidades y la territorialidad por parte de los Estados nacionales- son reemplazados por un modelo de colonialismo de red en el que las técnicas de individuación son controladas por grupos sub y supra nacionales, entre ellos los grupos religiosos. Frente a la desaparición del paradigma de la fijación del territorio, este nuevo modelo de territorialidad móvil se compone de espacios demarcados por las identidades de grupos y redes en movimiento que espectacularizan sus marcas identitarias. Asimismo, este modelo implica que la unidad de la población ya no está dada por su pertenencia a un territorio común sino que depende de una cohesión que se construye a partir de otras dimensiones compartidas. De este modo, Segato $(2007,2008)$ sostuvo la creciente centralidad del individuo y de las redes de grupos e instituciones religiosas en el control y la definición del espacio, proceso concomitante con la pérdida de hegemonía de los Estados nación. A su vez, llamó la atención sobre la interacción e integración de diferentes escalas espaciales -locales, nacionales, regionales y globales- en la composición del fenómeno religioso, estableciendo un punto de quiebre respecto de otros períodos históricos en los que el catolicismo 
desarrollaba políticas de creación de geografías religiosas que coincidían con los límites de la nación (Mallimaci, 2015).

A pesar de su diversidad, las investigaciones aquí reunidas comparten su mirada diacrónica y relacional entre agentes y grupos religiosos diversos. Ello les permitió reflexionar sobre las diferentes formas en que la presencia de lo religioso en la ciudad es interpretada por parte de distintos agentes, el papel de las prácticas religiosas en procesos de segregación urbana, y la construcción de modelos macro que dan cuenta de las diferentes formas que asume la relación entre Estado, espacio y modos de subjetivación.

\section{La religión y el espacio como categorías mutuamente influyentes}

El tercer conjunto de investigaciones aquí reunidas se caracterizan por comprender a la religión y al espacio como dimensiones mutuamente influyentes. Estas investigaciones buscan comprender del papel que ambas dimensiones juegan en los procesos de construcción de las identidades colectivas en la actualidad. Al igual que en los apartados anteriores, hacen foco en diversos objetos y dimensiones de la vida social : la residencia, los procesos migratorios transnacionales y las prácticas de ocio en las periferias y en las grandes urbes. Sin embargo, todas tienen en común el tomar a la vida religiosa y al espacio como elementos que tienen una agencia sobre la construcción de las identidades en las sociedades contemporáneas.

La primer investigación que compone este grupo es la compilación organizada por Odgers y Ruiz Guadalajara (2009) en la que se analizan los diferentes papeles que juegan prácticas y creencias religiosas en procesos migratorios y zonas fronterizas (Sánchez Molina, 2009; Giménez Béliveau, Setton y Montenegro, 2009). Los autores llamaron la atención sobre el importante carácter transformador que los procesos migratorios tienen en la vida religiosa de las comunidades de origen y de recepción. El estudio de diversos casos, muchos de ellos localizados en México y los Estados Unidos, les permite observar la recurrencia de dos fenómenos concomitantes: el de las continuidades identitarias y religiosas de los migrantes respecto de sus contextos de origen, así como la resignificación y sacralización de los contextos receptores. A pesar de la relevancia que el fenómeno migratorio ha tenido en América Central y del Norte durante las últimas décadas, Odgers y Ruiz Guadalajara (2009) advirtieron que la migración en general presenta una fuente importante de diversificación de las experiencias religiosas en América Latina ya desde los procesos de migración del campo a la ciudad a partir de mediados del siglo XX. Los trabajos compilados en este libro analizan el desplazamiento de creencias y prácticas religiosas de unos territorios a otros (Sánchez Molina, 2009), el papel de la religión en los procesos de construcción de identidades y de integración de los migrantes en los lugares donde se instalan (Robledo Hernandez, 2009), su función en el contacto simbólico y material con sus lugares de origen, y las formas en que símbolos religiosos son resignificados en los contextos de recepción de los colectivos migrantes y en zonas de fronteras (Giménez Béliveau, Montenegro y Setton, 2009).

Por su parte, Magnani (2016) ha desarrollado un importante conjunto de investigaciones en las que la religión es considerada una agencia que opera sobre la configuración 
del espacio y por sus apropiaciones por parte de diferentes redes de sociabilidad. En sus estudios sobre las prácticas de ocio en la ciudad y la periferia de San Pablo, el autor define a las prácticas como una parte de las actividades que contribuyen a la formación de lazos de solidaridad y de cercanía, y a la construcción de identidades particulares y espacializadas. Magnani construyó una serie de categorías que sintetizan esa relación entre espacio, sociabilidades y modos de vida. La primera de ellas, el "pedaço", hace referencia a un territorio pequeño, demarcado e identificado por determinados equipamientos que delimitan su oferta cultural, y habilitan el encuentro y la construcción de lazos (de vecindad, amistad, parentesco, gustos compartidos) entre actores sociales. Los pedaços se conforman en territorios de baja densidad poblacional donde los actores sociales que frecuentan determinadas prácticas suelen conocerse personalmente, como en los barrios periféricos de las grandes ciudades, y pueden ser el objeto de construcciones identitarias más amplias. La segunda de estas categorías, las "manchas" se extienden por territorios de mayor tamaño, generalmente en ámbitos urbanos, y, al igual que los pedaços, se configuran como puntos de referencia de frecuentadores que comparten relaciones de lealtad y de control. En este caso, las personas no necesariamente se conocen personalmente pero se reconocen por compartir gustos, orientaciones, valores, hábitos de consumo y modos de vida. Por último, la categoría de "circuito" hace referencia al conjunto de establecimientos distribuidos en un amplio territorio por los que circulan actores que desarrollan prácticas similares. A diferencia de las anteriores, la delimitación de los circuitos no está dada por un territorio determinado, sino por los trayectos de los actores, y por su reconocimiento como unidad significativa. Estas tres categorías hacen referencia, entonces, a espacios de diferente tamaño que presentan determinados equipamientos que habilitan la formación y el mantenimiento de sociabilidades por parte de actores que comparten un estilo de vida o una práctica común. En sus investigaciones sobre las periferias y el centro de la ciudad de San Pablo, Magnani (2016) analizó las religiones afrobrasileras como parte de los pedaços que se desarrollan en los barrios de la periferia, y a las prácticas vinculadas a la espiritualidad New Age, o neoesotéricas, como un circuito que se extiende por diferentes zonas de la ciudad asociadas a los sectores medios. Así este autor analizó la mutua influencia que religión y espacio ejercen entre sí al comprender a las prácticas religiosas y espirituales como parte de las prácticas colectivas que contribuyen con la definición y el reconocimiento del espacio $\mathrm{y}$, al mismo tiempo, como el producto de la influencia del espacio en las sociabilidades y los estilos de vida de los actores sociales que las habitan y transitan.

Desde una perspectiva similar, de Almeida (2009) afirmó que la ciudad no debe ser entendida como un "telón de fondo" o un paisaje sobre el que se desarrollan los procesos de transformación de las prácticas religiosas, sino una variable independiente que influye en ellas. Desde su perspectiva, las prácticas religiosas contribuyen a conformar el contexto urbano, es decir que ambos elementos son interdependientes. El autor desarrolló un estudio multiescalar del pluralismo religioso de la ciudad de San Pablo a través de la integración de tres estrategias metodológicas. En primer lugar, a través del georreferenciamiento de datos sobre identidades y prácticas religiosas, y su comparación con la georreferenciación de otros indicadores sociales (como el nivel educativo de los habitantes, y la renta de la tierra en distintas áreas y barrios de la ciudad), éste buscó 
identificar los perfiles sociodemográficos de los practicantes de distintas religiones y la forma en que se distribuyen en el espacio. Luego, estudió la distribución de los lugares de culto en relación con las transformaciones del contexto urbano, como los patrones residenciales, el crecimiento demográfico, la construcción de infraestructura urbana y los modos de circulación de los habitantes. Por último, estudió la distribución de las identidades religiosas en relación con la distribución de las condiciones de vida, etnografiar la manera en que la vida religiosa se articula con otras dimensiones de la vida cotidiana metropolitana. Análisis del Área Metropolitana de San Pablo.

Por último, cabe mencionar aquí la investigación que De la Torre y Gutiérrez Zúñiga (2015) llevaron adelante a partir del análisis cuantitativo de las prácticas religiosas no católicas en la ciudad de Guadalajara. El trabajo incorpora al análisis de la relación entre religión y espacio una dimensión que, si bien resulta central a la hora de pensar la experiencia espacial de los actores sociales, suele ser dejada de lado a la hora de pensar el espacio: la residencia. Las autoras estudiaron la relación entre religión y espacio a partir del impacto de las congregaciones religiosas en la diferenciación, dispersión y fragmentación del espacio urbano, sus respuestas a esas transformaciones a través de estrategias misioneras, y la relación que los creyentes establecen entre identificación y práctica religiosa con sus lugares de residencia. A partir del análisis de datos censales sobre las prácticas y la localización de lugares de culto de religiones no católicas en el Área Metropolitana de Guadalajara, De la Torre y Gutiérrez Zúńiga construyen una tipología de modelos territoriales religiosos. Al igual que en el caso de otras ciudades latinoamericanas en las que el catolicismo conserva su hegemonía, la selección de la población de estudio a partir de su carácter no católico se debe, en términos de las autoras, a la necesidad de problematizar la idea de que esa ciudad sea el "centro de operación católica de la región centro occidente del país" (de la Torre y Gutiérrez Zúńiga, 2015: 41) con mayor resistencia al cambio religioso, y de mostrar la diversidad religiosa en una zona que concentra la "infraestructura católica" del país, compuesta por seminarios, conventos, santuarios, colegios privados, hospitales religiosos y templos. De la Torre y Gutiérrez Zúniga (2015) se preguntan si los centros de culto contribuyen en la construcción de identidades barriales o si atraen a pobladores dispersos en el espacio urbano que construyen, entonces, un vínculo identitario alrededor de la asistencia al servicio religioso. A partir de allí, construyeron una tipología de estrategias territoriales de los lugares de culto para los contextos urbanos del siglo XXI. En primer lugar, los cultos que presentan una territorialidad nodal se caracterizan por una gestión monopólica del espacio por parte de una única institución religiosa que organiza y dota de sentido al conjunto de prácticas religiosas y relaciones sociales en dicho territorio. Muchas de las investigaciones aquí citadas coinciden en afirmar que este modelo prevaleció en América Latina alrededor de las instituciones católicas desde el período colonial hasta el desarrollo de procesos estructurales como el crecimiento demográfico y la secularización de la vida en las grandes ciudades. Sin embargo, este modelo prevalece en la actualidad en comunidades territoriales de práctica espiritual como ashrams o abadías. En segundo lugar, los casos de pertenencia religiosa heterogénea con hegemonía territorial segmentada se componen de comunidades religiosas que ejercen una hegemonía urbana que atraviesa la pertenencia a los barrios y que constituyen instituciones relevantes en la producción 
de sentido y de diferenciación dentro del espacio urbano. En Guadalajara, este es el caso de los Testigos de Jehová y de la Iglesia de Jesucristo de los Santos de los Últimos Días que logran fuertes identidades colectivas en sus espacios comunitarios a pesar de que sus seguidores no comparten un lugar de residencia ni una identidad barrial. En tercer lugar, la pertenencia emotiva a una comunidad creyente con territorialidad dispersa e identificación difusa hace referencia a los grupos religiosos que, como en el caso de varias iglesias evangélicas, no presentan una identidad denominacional anclada a un único territorio pero construyen una comunidad imaginada más allá de las pertenencias inestables de sus fieles que circulan por diferentes lugares de culto. Por último, la categoría de multipertenencias religiosas con territorialidad dispersa engloba a aquellos actores sociales que a lo largo de sus trayectorias vitales pertenecen a diferentes cultos localizados en diferentes partes de la ciudad.

Este último conjunto de investigaciones se caracteriza, entonces, por comprender a la vida religiosa y al espacio como dimensiones mutuamente influyentes. Uno de sus aportes significativos a la reflexión sobre la dimensión espacial de la religión está dado por su atención sobre aspectos de la vida social poco explorados por aquellas investigaciones que se concentran en amplios territorios, como la ciudad o la metrópolis. Aquí, en cambio, la mirada se coloca sobre territorios que resultan significativos en las experiencias cotidianas de los creyentes, como los barrios y las residencias. Es por ello que las investigaciones de este último apartado integran a la reflexión sobre las relaciones entre espacio y religión una dimensión que media ambas: la de las identidades colectivas.

\section{A modo de cierre}

En este artículo se presentaron algunas de las principales investigaciones que durante las últimas décadas exploraron la relación entre religión y espacio en América Latina. La dimensión territorial como un aspecto significativo de la vida religiosa en nuestras sociedades no emergió en las agendas de investigación locales hasta fines del siglo XX. Sin embargo, como se pudo constatar a lo largo del artículo, durante los últimos ańos proliferaron investigaciones que, basadas en evidencia empírica, problematizaron dicha relación desde diferentes aristas. Como intentamos mostrar a lo largo de este artículo, la emergencia del espacio como una dimensión significativa, entonces, puede orientar nuestra mirada hacia una multiplicidad de fenómenos que influyen y se ven influidos por la vida religiosa.

En primer lugar, identificamos un conjunto de estudios orientados hacia la comprensión de la territorialización de la religión y su influencia en los usos y semantizaciones del espacio público. Un segundo conjunto abordó los diferentes roles e interpretaciones que asumen las prácticas religiosas frente a procesos de transformación urbana en diferentes contextos históricos. En ambos casos, el estudio de la dimensión espacial de la vida religiosa permite comprender los procesos de regulación que limitan la práctica y expresión pública de algunos grupos religiosos. Finalmente, el último conjunto de trabajos seleccionados comprende a la religión y el espacio como dimensiones mutuamente influyentes que, al mismo tiempo, moldean las identidades colectivas en las sociedades contemporáneas. 
El espacio en los estudios sociales de la religión...

\section{Referências}

Algranti, Joaquin, Calcagno, Nicolás, Gimenez Béliveau, Verónica, \& Rubio, Berenice. (2013). Marcas religiosas en el Área Metropolitana de Buenos Aires. En Mallimaci, Fortunato (Dir.), Atlas de las creencias religiosas en la Argentina (pp. 236-241). Buenos Aires: Biblos.

Ameigeiras, Aldo. (2008). Religiosidad popular: Creencias religiosas populares en la sociedad argentina. Los Polvorines: Universidad Nacional de General Sarmiento.

Bahamondes, Luis. (2016). Aproximaciones al estudio de la mercantilización de lo sagrado en la ciudad de Santiago de Chile. Newsletter de la Asociación de Cientistas Sociales de la Religión del MERCOSUR (ACSRM), 34.

Beaumont, Justin, \& Baker, Christopher. (2011). Postsecular Cities: Space, Theory and Practice. Londres: Cotinuum.

Becci, Irene, Burchardt, Marian, \& Casanova, José. (2013). Topographies of Faith: Religion In Urban Spaces. Leiden: Brill.

Becci, Irene, Burchardt, Marian, \& Giorda, Mariachiara. (2017). Religious superdiversity and spatial strategies in two European cities. Current sociology, 65, 73-91.

Blazsek, Andrea, Galiotti, Carolina, Lisboa, Marcela, Melonari, Erica, Ortiz, Gustavo, Potaschner, Ezequiel, ... Sosa, Lucia. (2013). Marcas religiosas en el Gran Mendoza: Territorios y espacios. En Mallimaci, Fortunato (Dir.), Atlas de las creencias religiosas en la Argentina (pp. 220-227). Buenos Aires: Biblos.

Carballo, Cristina. (2008). Buenos Aires y las creencias religiosas: Un mapa inestable. Revista universitaria de geografía, 17, pp. 29-54.

Ceriani Cernadas, César, \& Lavazza, Hugo. (2013). Fronteras, espacios y peligros en una misión evangélica indígena en el Chaco Argentino (1935-1962). Boletín Americanista, 2(67), 143-162.

de Almeida, Ronaldo. (2009). Pluralismo religioso e espaco metropolitano. En Mafra, Clara \& de Almeida, Ronaldo (Orgs.), Religióes e cidades. Rio de Janeiro e Sáo Paulo (pp. 29-50). Terceiro Nome.

De la Torre, Renée, \& Gutiérrez Zúñiga, Cristina. (2015). Ceer, habitar y practicar el territorio: Tipos ideales de identidad y residencia en los cristianos no católicos de Guadalajara, Jalisco. Espacialidades, 5(2), pp. 38-76.

Fer, Yannick. (2007). Pentecôtisme et modernité urbaine: Entre de' territorialisation des identités et réinvestissement symbolique de l'espace urbain. Social Compass, 54(2), 201-210.

Flores, Fabián. (2012). Luján como hierópolis: Del relato espacial al lugar religioso. Revista Universitaria de Geografía, 21, pp. 137-158.

Flores, Fabián. (2017). Peregrinos a Luján. Hacia la madre gaucha. 14-17. 
Flores, Fabián. (2018). La colina de la Esperanza. Espacialidad y religiosidad en los orígenes de la aldea adventista de Puiggari (Ediciones Ilustre). Buenos Aires.

Frigerio, Alejandro. (2002). Outside the Nation, outside the Diaspora: Accommodating Race and Religion in Argentina. Sociology of Religion, 63(3), pp. 291-315.

Garbin, David, \& Strhan, Anna. (2017). Religion and the Global City. London: Bloomsbury Academic.

Giménez Béliveau, Verónica, \& Martínez, Ana Teresa. (2013). Símbolos religiosos en el espacio público. En Atlas de las creencias religiosas en la Argentina (pp. 217-240). Buenos Aires: Biblos.

Giménez Béliveau, Verónica, Montenegro, Silvia, \& Settón, Damián. (2009). "Árabes en la selva». Migración, religión e identidad en el imaginario de católicos y pentecostales. En O. Odgers Ortiz \& Ruiz Guadalajara, Juan Carlos (Comp.), Migración y creencias. Pensar las religiones en tiempos de movilidad. (pp. 101-129). México: El Colegio de la Frontera Norte.

Giumbelli, Emerson. (2014). Introdução: O que os símbolos fazem para redefinir a religião. En Símbolos religiosos em controvérsias (pp. 11-21). San Pablo: Terceiro Nome.

Giumbelli, Emerson, Heberle, Fernanda, Kerber, Monica, Tavares, Fatima, \& Giumbelli, Emerson (Org.). (2015). Religião, cidade e modernização: Três casos distintos em Porto Alegre. En Religióes e temas de pesquisa contemporâneos: Diálogos antropológicos (pp. 97-119). Salvador: EDUFBA.

Halbwachs, Maurice. (2015). La topografía legendaria de los Evangelios en Tierra Santa. Madrid: Centro de Investigaciones Sociológicas.

Hérvieu-Léger, Danielle. (2002). Space and religion: New approaches to religious spatiality and modernity. International Journal of Urban and Regional Research, 26, 99-105.

Magnani, José Guilherme Cantor. (2016). São Paulo: De perto (e de dentro) é outra cidade. Ponto Urbe, 18. https://doi.org/10.4000/pontourbe.3116

Mallimaci, Fortunato. (2015). El mito de la Argentina laica. Catolicismo, política y Estado. Buenos Aires: Capital Intelectual.

Martínez, Ana Teresa, Miguel, Gloria, \& Remedi, Roberto. (2013). Marcas religiosas en el espacio público de la ciudad de Santiago del Estero. En Mallimaci, Fortunato (Dir.), Atlas de las creencias religiosas en la Argentina (pp. 220-227). Buenos Aires: Biblos.

Miguel, Gloria. (2014). Territorio urbano y lugares religiosos. Una aproximación al análisis de las inscripciones territoriales religiosas en la ciudad de Santiago del Estero. Trabajo y Sociedad, 22, pp. 195-203. 
Nicoletti, María Andrea, \& Barelli, Inés. (2014). Devociones marianas en la ciudad de San Carlos de Bariloche (Argentina): Construcciones identitarias sociales y marcas territoriales. Revista Brasileira de História das Religióes, 19(7), pp. 05-30.

Núñez, Paula Gabriela, \& Barelli, Inés. (2013). Marcas urbanas y sentidos sociales en disputa. San Carlos de Bariloche, Argentina 1966-1983. Historielo, 5(10), pp. 166-195.

Odgers-Ortíz, Olga, \& Ruiz Guadalajara, Juan Carlos. (2009). Introducción. En O. Odgers Ortiz \& Ruiz Guadalajara, Juan Carlos (Comp.), Migración y creencias. Pensar las religiones en tiempos de movilidad. (pp. 05-09). México: El Colegio de la Frontera Norte.

Passos, João Décio, \& Guerriero, Silas. (2004). Metamorfoses religiosas no centro de Sáo Paulo. Ciencias Sociales y Religión/Ciências Sociais e Religião, 6(6), pp. 117-133.

Robledo Hernández, Gabriela. (2009). Translocalidad y protestantismo popular en el altiplano chiapalteco. En O. Odgers Ortiz \& Ruiz Guadalajara, Juan Carlos (Comp.), Migración y creencias. Pensar las religiones en tiempos de movilidad. (pp. 303-330). México: El Colegio de la Frontera Norte.

Sánchez Molina, Raúl. (2009). Pentecostalismo y transnacionalismo: Inmigrantes salvadoreños y la iglesia de los apóstoles y profetas en Washington D.C. En O.

Odgers Ortiz \& Ruiz Guadalajara, Juan Carlos (comp.), Migración y creencias.

Pensar las religiones en tiempos de movilidad. (pp. 241-264). México: El Colegio de la Frontera Norte.

Segato, Rita. (2007). Formaciones de Alteridad: Nación y cambios religiosos en el contexto de la globalización. En Segato, Rita, La Nación y sus Otros (pp. 175-201). Buenos Aires: Prometeo.

Segato, Rita. (2008). La faccionalización de la república y el paisaje religioso como índice de una nueva territorialidad. En Alonso, Aurelio (comp.), América Latina y el Caribe: Territorios religiosos y desafíos para el diálogo (pp. 41-81). Buenos Aires: CLACSO.

Seiguer, Paula. (2015). Laicidad y pluralidad religiosa temprana. Los metodistas y el Estado laico en la década de 1880. Quinto Sol, 19, 01-22.

Suárez, Hugo José. (2017). La geografía de la práctica religiosa en una colonia popular en la ciudad de México. Sociedad y Religión, 27(47), 07-11.

Recebido: 15 de julho de 2019.

Aprovado: 27 de agosto de 2019. 